\title{
Close ties, near and far away: patterns and predictors of geographic network range among older Europeans
}

\author{
Haosen Sun $^{1}$ D . Markus Schafer ${ }^{1}$ \\ Accepted: 3 December 2021 / Published online: 24 December 2021 \\ (c) The Author(s), under exclusive licence to Springer Nature B.V. 2021
}

\begin{abstract}
A growing number of older adults maintain connections in their core discussion networks at variant distances, raising concerns about the lack of discussants in proximity and the consequences on their social life. This study examines the typical geographic layouts for aging Europeans' core discussion networks and their implications for network function and quality. With a sample of community-dwelling respondents aged 50 and above from the Survey of Health, Aging, and Retirement in Europe, the present research identifies seven geographic layouts that extend previously identified family and diverse network types by adding spatial nuance. Individuals in mid-range and distant-family networks typically lack a discussant nearby but sustain high emotional closeness with family discussants at a distance and express high overall satisfaction with their network. Proximate-diverse networks with a strong representation of non-kin members nearby turn out to be less advantageous than prior research might suggest, providing relatively frequent contact but the lowest level of network satisfaction. Results also identify how individual characteristics link to the geographic layouts and describe their prevalence across European regions. Overall, relatively dispersed layouts are common for older adults across multiple countries and do not necessarily indicate lower emotional closeness and network satisfaction. The present study highlights the importance of looking beyond the mere presence of proximate connections in older adults' core networks.
\end{abstract}

Keywords Network typology $\cdot$ Geographic layouts $\cdot$ Non-proximate connections $\cdot$ Family and non-kin compositions · European regions

\section{Introduction}

Social connectedness is beneficial for older adults' sense of well-being and promotes successful aging by providing opportunities for social engagement and social support in times of need (Cornwell et al. 2008; Litwin et al. 2019). Frequent contact and high emotional closeness with network connections facilitate support exchanges and promote the relationships' continuity (Klein Ikkink and van Tilburg 1999; Hank 2007; Ashida and Heaney 2008; Cornwell et al. 2008; Goldman and Cornwell 2018). Furthermore, older people who are satisfied with the support and resources available through their network report low levels

Responsible editor: Marja J.Aartsen.

Haosen Sun

haosen.sun@mail.utoronto.ca

1 Department of Sociology, University of Toronto, Toronto, ON, Canada of loneliness and high overall quality of life (Perlman and Peplau 1981; Vozikaki et al. 2018; Schmidt et al. 2021). When explaining variation in the function and quality of networks, many gerontologists focus on the geographic proximity between older adults and their network members, a factor that sets the opportunity structure for their social interactions and support exchanges (Bengtson 2001; Hank 2007; Cornwell and Goldman 2021). Existing research has focused on older adults' local embeddedness and the availability of local connections in their networks, especially among family members such as children (e.g., Wenger 1991; Tomassini et al. 2004; Litwin and Shiovitz-Ezra 2011). Besides being available for companionship, connections located nearby can also react more quickly to the rising needs of older adults, especially when it comes to favors and assistance requiring physical co-presence (Fischer 1982; Logan and Spitze 1994; Klein Ikkink and van Tilburg 1999; Frei and Axhausen 2007; Small and Adler 2019).

Nevertheless, many older adults also maintain connections over longer distances. Such diversity is part of the 
trend of networked individualism, where people's relationships shift from local, densely connected communities toward multiple far-reaching, loosely knit, and personalized networks (Harper et al. 2020). Adults in more recent cohorts have fewer children than their older peers-and these adult children are also more likely to live farther away from their parents to pursue career opportunities and build families (Hank 2007). Likewise, other extended family members can also remain part of older adults' core networks, even when they are not living nearby (Koelet et al. 2017). Non-kin connections could be more vulnerable to distance than family ties, as they rely more on continuous reciprocity and mutual satisfaction than familial normative expectations and obligations (Wellman 1992; Suanet and Antonucci 2017). Nevertheless, some non-kin relationships are more resilient to longer ranges than others, especially when their sentimental value and proven reliability outweigh the reduced reciprocity over longer distances (Fischer 1982; de Jong Gierveld and Perlman 2006). Thanks to technological developments, older adults can better sustain many connections over longer distances and enjoy more interactions, emotional support, and shared moments with them, which promotes a sense of engagement and belonging (Quan-Haase et al. 2017; Harper et al. 2020).

Still, it is not clear how older individuals typically mix family and non-kin connections located at variant distances in their core networks, how these different geographic layouts associate with individual characteristics, and-most importantly - whether and how diverse geographic layouts link to variation in the function and quality of older adults' core discussion networks. These questions have gained significance in light of the higher prevalence and acceptance of long-range connections, increased options to keep in touch, diverse cultural traditions across European regions and varied individual characteristics. An up-to-date answer to these questions should contribute a unique perspective on which older adults are at risk of isolation and inform subsequent efforts to understand the implications of proximal vs. farflung connectivity for well-being in old age.

The present research develops a typology dedicated to social networks' geographic layout among older adults in the European context, highlighting both families and nonkin connections beyond arm's reach. We further interpret the identified geographic structures in the context of older adults' social demographic characteristics. In addition, to reveal whether some geographic layouts function differently from others, we examine how they associate with one's network contact, closeness with network connections, and network satisfaction. We use data from the sixth wave of the Survey of Health, Ageing, and Retirement in Europe (SHARE), which provides detailed information on the core networks of the aging population.

\section{Background}

\section{Network typologies}

Building network typologies is a well-established approach to summarize complex social network contexts and experiences in the aging population. Instead of focusing on a single dimension of networks measured by a single variable, a typology approach considers multiple attributes of networks, such as one's network size, locality of connections, diversity of ties, frequency of contact with members, and one's participation in group activities. Existing typologies have consistently identified several types of networks, namely diverse, friend-focused, family-focused, and restricted networks. Older adults embedded in diverse networks with a mixture of family and friend connections are likely to enjoy higher levels of well-being and physical, mental, and cognitive health. In contrast, individuals in restricted networks tend to report the worst outcomes (e.g., Litwin 2001; Fiori et al. 2006; Litwin and Shiovitz-Ezra 2006, 2011; Park et al. 2014; Stoeckel and Litwin 2016; Djundeva et al. 2019; Cohn-Schwartz et al. 2020). Diverse and friend-focused networks appear to provide benefits because they incorporate members on a voluntary basis (Antonucci and Akiyama 1995; Cheng et al. 2009; Litwin and Shiovitz-Ezra 2011; Fiori and Jager 2012) and provide opportunities for engagement in social activities and integration to the broader society (Fiori et al., 2006; Golden et al., 2009; Djundeva et al., 2019). Diverse networks are also more likely to provide a broader range of support than homogeneous family networks can offer, covering diverse needs for instrumental, emotional, and advisory support (Aartsen et al. 2004; Ellwardt et al. 2017).

\section{From network proximity to geographic layouts}

A more thorough consideration of geographic distance can further enrich these significant contributions of network typology research. It has become more common for older adults to sustain family connections over longer distances, as a result of higher life course residential mobility in both older and younger generations, family complexities, and preferences for intimacy at a distance (Rosenmayr and Köckeis 1963; Finchum 2005; Hank 2007; Viry 2012; Wrzus et al. 2013; Goldman and Cornwell 2018; Fihel et al. 2021). Although long-range connections with friends and non-kin can discontinue when reciprocity is limited, some special relationships persist over time regardless of the distance barrier (Fischer 1982; Viry 2012; Harper et al. 2020). In the face of such complexities, "diverse" networks are likely to vary not only in relationship composition but 
also in proximity, as individuals adjust their social convoy to their changing needs and life circumstances. For example, individuals can opt to form or rekindle local non-kin connections in place of or supplement non-proximate-family connections for general support (Cornwell and Goldman 2021; Iveniuk et al. 2020; Fihel et al. 2021). Meanwhile, following social-emotional selectivity theory (Carstensen, 1992), older individuals could opt to focus on relationships that provide the most emotional satisfaction and support, particularly family members. This may still apply when the family connections are located at longer distances.

Unfortunately, however, existing network typologies fall short in identifying the rising diversity of the geographic layouts of older adults' core networks. It is partly because they often opt to employ a simple aggregate measure of the overall nearness of one's connections, possibly as a trade-off to incorporate a broad array of network attributes. Examples of such measures include older adult's distance to the nearest family member, such as a child, relative, and sibling (Wenger 1991; Szabo et al. 2016); the number of connections or adult children residing in the vicinity (Litwin 2001; Litwin and ShiovitzEzra 2006; Djundeva et al. 2019); and proportion of network members living nearby, such as in the same city (Fiori et al. 2007), in an hour's drive (Fiori et al., 2008), and within a $5 \mathrm{~km}$ radius (Litwin and Stoeckel, 2013). Other typology studies have excluded the proximity factor altogether (e.g., Fiori et al. 2006; Nguyen 2017; Sohn et al. 2017). Simply counting connections located nearby (e.g., within one's $5 \mathrm{~km}$ radius) discards information about more distant connections, whereas the proportion in proximity is heavily influenced by one's partnership status, especially when network sizes are small. Further, the meaning of the proportion of connections in proximity is potentially misleading, especially when interpreted as a standalone measure without specifying network size. For example, someone living together with a partner as the only member in the core network would demonstrate $100 \%$ network proximity. Meanwhile, their counterpart with an additional child or friend located out of the $5 \mathrm{~km}$ radius would show $50 \%$ network proximity but have arguably richer social connectedness and access to support. Consequently, existing typologies have little to say about networks with increasingly diverse geographic layouts, which could be nevertheless active and supportive. The present study offers a more comprehensive description of geographic layouts by simultaneously considering a range of proximity options and the composition of network members.

\section{Factors shaping network types and geographic layouts}

Prior research has revealed that network type is a function of demographic traits and contextual variables. Individuals at older ages, with low education and income, who are not married, and who suffer physical limitations tend to occupy restricted or family-focused networks (Litwin 2001, 2003, 2010; Fiori et al. 2006, 2007, 2008; Fiori and Jager 2012; Djundeva et al. 2019). These characteristics often also correlate with higher network proximity, considering that disadvantaged individuals in higher need of support and care often have limited residential mobility and prefer to live close to their families (Spring et al. 2017; Jacobs et al. 2018; Cornwell and Goldman 2021). In contrast, individuals with diverse network members may also sustain such configurations across diverse geographic layouts. Research has identified that older adults in diverse network types tend to be relatively young, educated and high-earning, engaged in community activities, and in good functional health (Wenger et al. 1996; Litwin 2001; Fiori et al. 2006, 2008; Fiori and Jager 2012; Cornwell and Goldman 2021). These individuals often have more local non-kin connections from joint activities and may discuss important matters with them due to their domain knowledge and easy accessibility (Small, 2013; Fihel, 2021). On the other hand, individuals with the most resources often have had the highest lifetime residential mobility. They are also most likely to have the resource and willingness to sustain their connections with family and friends beyond proximity or revive them when needed (Finchum 2005; Bloem et al. 2008; Viry 2012; Harper et al. 2020). In summary, our study will incorporate predictors from earlier research to describe how our geographicfocused typology converges or departs from conventional typologies.

In the spirit of exploratory analysis, we incorporate several factors not yet widely present in network typology research that home in on the geographic dimension of networks. First, urbanization has raised concerns about weaker social bonds with community and family members, especially in areas clustered with low-income older adults and among individuals in residential instability (Wrzus et al. 2013; Vriens and van Ingen 2018a; Menec et al. 2019). Nevertheless, urban areas also offer higher accessibility to social institutions and more opportunities for informal socializing (Stoeckel and Litwin 2015; Small and Adler 2019; Torres 2019; Cornwell and Goldman 2021). In contrast, people in rural areas are more likely to embed in local family-focused networks (Logan and Spitze 1994; Djundeva et al. 2019). Meanwhile, younger adults often move away from rural areas after graduating from universities (Rérat 2014; Lovén et al. 2020) and thereby become long-range connections in their parent's core network. Second, although communication technologies have alleviated geographic constraints on one's access to support from core confidants, older adults are less likely than the young to be proficient or active users (Mok et al. 2010; Harper et al. 2020; Cornwell and Goldman 2021). Limited digital skills can make it harder to sustain core connections over longer distances, though many older 
adults actively develop these skills when such need arises (Quan-haase et al. 2018; Harper et al. 2020). Third, older adults often direct their attention and support to their adult children when becoming grandparents (Kaptijn et al. 2010; Bucx et al. 2012; Hogerbrugge and Silverstein 2014). They often strengthen their family connections, especially those in proximity, which may take time and energy from nonkin connections. Fourth, activity participation contributes to social engagement and developing friendships, especially in one's locality (Fischer 1982; Fiori et al. 2007; Iveniuk et al. 2020; Cornwell and Goldman 2021).

The distribution of different geographic layouts is also likely to vary across European countries and regions. Older adults in the more familistic southern and eastern European countries tend to have higher reliance and expectations on family members for support (Reher 1998; Dykstra 2018). We expect they are most likely to have networks primarily consisting of family members living nearby. Meanwhile, Northern and Western European countries have higher levels of individualism and more generous welfare support. Older adults in these countries tend to have higher engagement with friends in their core networks (Litwin and Stoeckel 2013) and are more likely to live far from their children (Hank 2007). More robust welfare support tend to promote independent living and alleviate reliance on proximate-family support (Kohli et al. 2009; Mudrazija et al., 2020). In this way, we would expect older adults in Northern and Western Europe to have more non-relatives in their core networks and display more dispersed geographic layouts.

\section{Geographic layouts and network function and qualities}

A clear picture of network geographic layouts can further help to reveal how such diverse structural settings affect the core networks' function and quality, namely frequency of contact, emotional closeness, and people's overall satisfaction with their network.

As a primary indicator of tie strength, frequency of contact is considered a conduit for multiple forms of support. Frequent interactions allow people to communicate about their needs and facilitate the exchange of resources (Kalmijn 2006; Ward et al. 2014; Goldman and Cornwell 2018). Higher contact with network members also contributes to higher network stability (Goldman and Cornwell 2018; Perry et al. 2018). At the same time, contact frequency is an aspect of networks that may be especially sensitive to distance. Although technological developments have offered convenient and low-cost options to maintain contact with ties over substantial distances and enable companionship, emotional support, and access to information (Harper et al. 2020), people still appear to talk most often to those in their local community. Phone conversations, for instance, are concentrated at close range and are relatively rare beyond close driving distance (Mok et al. 2010). Even between parents and their children, a distance-increasing move leads to less conversation, while moving closer by has the opposite effect (Ward et al. 2014). Therefore, it seems plausible that geographically proximate networks, on average, enable higher contact volume.

Emotional closeness to network members and overall satisfaction with one's network may be similarly—or perhaps more-responsive to distance. However, it remains unclear to what extent core networks stretching across various distances differ in these dimensions of network quality. Though technology likely offers some help in sustaining emotional closeness and network satisfaction, virtual interactions appear less effective than in-person connection for providing on-spot supports, especially minor assistance in daily life (Fischer 1982; Frei and Axhausen 2007). Further, the lack of cues in online communication can also limit exchanges of complex ideas and deep feelings (Vriens and van Ingen 2018). These drawbacks may have important implications for the quality of distant networks layouts. In sum, as long as virtual and face-to-face interactions remain distinct, we expect some of the more geographically expanded layouts to be associated with lower overall contact frequency and emotional closeness with network members, as well as lower overall network satisfaction.

\section{Summary of present study}

To summarize, the goal of the present research is twofold. First, we aim to develop a typology of older Europeans' core social networks focusing on the geographic layouts, examining their prevalence across European regions and their correlation with individual characteristics. Second, we consider how geographic layouts - as structural features of personal networks - are associated with the function and quality of older adults' networks, including contact and emotional closeness with one's connections and overall satisfaction with the network.

\section{Methods}

\section{Data and sample}

The current study uses the sixth wave of the SHARE collected in 2015, covering 18 countries, including Austria, Germany, Sweden, Spain, Italy, France, Denmark, Greece, Switzerland, Belgium, Israel, Czech Republic, Poland, Luxembourg, Portugal, Slovenia, Estonia, and Croatia (BörschSupan et al. 2013; Malter and Börsch-Supan 2017; BörschSupan 2020). The data were collected by computer-assisted personal interviews (CAPI) in the respondent's home in the 
local language. SHARE used a country-specific probability sampling approach to maximize population coverage and offered calibrated weights to compensate for potential selection effects from non-responses and panel attrition. The sixth wave of SHARE contained a social network module, featuring detailed information on one's ego-centric network collected through a name generator approach, which serves as the foundation of the present analysis. We focus on community-dwelling respondents aged 50 and above living in Europe who could answer the questionnaire themselves. To be included in the sample, respondents should have participated in the Social Network Module and identified at least one network connection. We exclude respondents with missing data through listwise deletion, common in research using SHARE (missing $<5 \%$ for each variable). The final analytical sample consists of 35,003 older adults. We also verified our analysis using multiple imputations with chained equations; results were robust to either missing data strategy.

\section{Indicators for geographic layouts in core discussion networks}

We use the name generator provided in the social network module to produce respondents' core networks and identify their layouts. The generator asked: "Most people discuss with others the good or bad things that happen to them, problems they are having, or important concerns they may have. Looking back over the last 12 months, who are the people with whom you most often discussed important things?" After collecting the names, the name generator further identified one's relationship with and distance from each network member. We regroup the relationships into relatives and non-relatives. Also, to avoid restrictively small categories, we recode respondents' distance from each network member from eight to four groups, including: in the same household, within $5 \mathrm{~km}$, between 5 and $25 \mathrm{~km}$, and more than $25 \mathrm{~km}$ (original groupings were: in the same household; in the same building; $<1 \mathrm{~km} ; 1-5 \mathrm{~km} ; 5-25 \mathrm{~km} ; 25-100 \mathrm{~km}$; $100-500 \mathrm{~km}$; and $>500 \mathrm{~km}$ ). We choose these cut points because a $5 \mathrm{~km}$ radius best represents a local community that allows frequent unplanned face-to-face interaction, whereas $25 \mathrm{~km}$ around one's residence represents an area covered by public transit or casual visiting with some planning (Fischer 1982).

From this information, we construct seven dichotomous variables as indicators for LCA. Each indicator shows whether one has a family or a non-kin connection at the following distances: in the household (only for family), within $5 \mathrm{~km}$, between 5 and $25 \mathrm{~km}$, and more than $25 \mathrm{~km}$ away. Since non-kin connections are rarely in the same household, we reclassify the most proximal category of non-kin ties as within $5 \mathrm{~km}$. In this way, we have a total of 7 indicators $=1$ (family connection in the household) +2 relationships $\times 3$ distances. We use these indicators for LCA to identify the typical geographic layouts in older Europeans' core discussion network.

\section{Factors associated with network layouts}

We have also considered a range of individual characteristics that are associated with one's network layouts, including older adults' education, household financial standing, self-reported computer skills, network size, participation in organized social activities, age, gender, marital status, childlessness, self-rated health, mobility limitations, grand-parent status, and urbanization in the area of residence. Detailed information on operationalization and measurement of these variables is available in appendix.

\section{Network function and quality}

We consider three dimensions of the function and quality of older adults' core discussion networks: contact with network members, average emotional closeness to network ties, and overall network satisfaction. Respondents reported the contact frequency with each network member, ranging from $1=$ monthly or less to $6=$ daily contact. We sum up the responses to develop a network contact scale (mean $=13.33$, $\mathrm{SD}=6.93$ ). Respondents also reported their perceived closeness with each network member, ranging from $0=$ not very close to $4=$ extremely close. We take their average to summarize one's emotional closeness with network members (mean $=3.28, \mathrm{SD}=0.59)$. Respondents' overall network satisfaction measures "how satisfied are you with the relationships you have with all the people we have just talked about?", which takes an integer value ranging from $0=$ completely satisfied to $10=$ completely satisfied (mean $=9.00$, $\mathrm{SD}=1.20$ ).

\section{Analytic strategy}

Our first step is to identify and interpret the geographic layouts of older adults' social networks. We conduct latent class analyses (LCA) using Mplus 8.6, using the presence of family and non-kin connections at various distances in the networks as indicators. As a data reduction technique, LCA can identify unobserved groups in the sample based on a set of categorical indicators; the method also estimates each participant's group membership based on the highest estimated probability among the groups (Collins and Lanza 2009; Lynch and Taylor 2016). We identify the optimal number of classes based on model fit indicators such as Akaike's information criterion (AIC), Bayesian information criterion (and its sample size adjusted version, BIC/ SSC-BIC), entropy, and the results of model improvement tests (VLMR, LMR, and BLRT significance) (Collins and 
Lanza 2009, 2010). We then interpret each identified sociogeographic layout based on the conditional probabilities of the indicators. Second, we used multinomial logistic regression to reveal how individual characteristics are associated with the geographic layouts and examined their prevalence across European regions. In the third and final step, we used ordinary least squares (OLS) regression to examine how geographic layouts as structural factors correlate with network function and quality, namely older adults' contact and emotional closeness with core network members as well as their overall satisfaction with the network.

\section{Results}

\section{Geographic layouts}

We fit models for 1-8 latent classes and confirm that the seven-class solution is optimal. It has the lowest BIC (and its sample size adjusted version, SSC-BIC) and the highest entropy (0.814) among the solutions while offering reasonable group sizes. Although the eight-class solution's AIC is slightly lower, its entropy (0.76) was lower than the sevenclass solution with a higher SSC-BIC. The fit statistics for the models with 1-8 latent classes are available in Appendix Table 1 . We assign each respondent to the class whose probability was highest according to the LCA. The classification probabilities for the most likely latent class membership range from 0.71 to 1 , showing a reasonable level of certainty in assigning individuals to a specific latent class.

We present the seven latent classes in Table 1, followed by the multinomial logistic regression of geographic layouts on individual characteristics in Table 2. We present the results in average adjusted predictions (AAPs) and average marginal effects (AMEs) to show who is in which geographic layout. The AAPs show the predicted probability of the dependent variable for individuals in a particular group, asserting everyone to a specific category of the independent variable while keeping other variables at their actual values for each respondent. The AMEs further show the differences in the AAPs between groups, or the effect of a unit change in each independent variable.

The first four network layouts are predominantly familyoriented. The first layout we identify is household-based networks, in which older adults have at least one family discussant in the same household (18.25\% of the sample). In contrast, external connections with family and non-kin are both limited. As shown in the AMEs in Table 2, older adults who are younger, male, married, in good health, and without young grandchildren are especially likely to have a household-based network, as are those with limited education and not participating in organized activities.

We name the second group proximate-family networks, as it comprises people who mentioned family connections

Table 1 Characteristics of networks identified by latent class analysis (Class $=7$ )

\begin{tabular}{|c|c|c|c|c|c|c|c|}
\hline $\begin{array}{l}\text { Identified latent } \\
\text { classes }\end{array}$ & Class 1 & Class 2 & Class 3 & Class 4 & Class 5 & Class 6 & Class 7 \\
\hline Network layouts & Household-based & $\begin{array}{l}\text { Proximate- fam- } \\
\text { ily }\end{array}$ & Mid-range family & Distant- family & $\begin{array}{l}\text { Proximate } \\
\text { diverse }\end{array}$ & $\begin{array}{l}\text { Expanded- } \\
\text { diverse }\end{array}$ & $\begin{array}{l}\text { Far-reach- } \\
\text { ing-diverse }\end{array}$ \\
\hline \multicolumn{8}{|l|}{ Indicator } \\
\hline Prevalence in $\%$ & $18.25 \%$ & $25.23 \%$ & $9.80 \%$ & $8.87 \%$ & $20.76 \%$ & $11.49 \%$ & $5.60 \%$ \\
\hline \multicolumn{8}{|c|}{ Having one or more: } \\
\hline $\begin{array}{l}\text { Family in } \\
\text { household }\end{array}$ & 1 & 0.475 & 0.542 & 0.651 & 0.323 & 0.363 & 0.442 \\
\hline $\begin{array}{c}\text { Family in } \\
0-5 \mathrm{~km}\end{array}$ & 0.119 & 1 & 0.08 & 0.099 & 0.32 & 0.276 & 0.182 \\
\hline $\begin{array}{l}\text { Family in } \\
5-25 \mathrm{~km}\end{array}$ & 0.044 & 0.231 & 1 & 0.067 & 0.229 & 0.298 & 0.125 \\
\hline $\begin{array}{l}\text { Family } 25 \mathrm{~km} \\
\text { and above }\end{array}$ & 0 & 0.22 & 0.301 & 1 & 0.298 & 0.298 & 0.49 \\
\hline $\begin{array}{l}\text { Non-kin in } \\
0-5 \mathrm{~km}\end{array}$ & 0.061 & 0.094 & 0.034 & 0.099 & 1 & 0.38 & 0.31 \\
\hline $\begin{array}{c}\text { Non-kin in } \\
5-25 \mathrm{~km}\end{array}$ & 0.025 & 0.022 & 0.062 & 0.055 & 0.044 & 1 & 0.151 \\
\hline $\begin{array}{l}\text { Non-kin } \\
25 \mathrm{~km} \text { and } \\
\text { above }\end{array}$ & 0.012 & 0.018 & 0.061 & 0.025 & 0.05 & 0.19 & 1 \\
\hline
\end{tabular}

The proportions show the prevalence of each network type in the sample, which add up to $100 \%$. The probabilities show the chance of having a certain type of connection in a network layout 
Table 2 Multinomial logistic regression of the geographic layouts (results in AME)

\begin{tabular}{|c|c|c|c|c|c|c|c|}
\hline $\begin{array}{l}\text { Identified latent } \\
\text { classes }\end{array}$ & Class 1 & Class 2 & Class 3 & Class 4 & Class 5 & Class 6 & Class 7 \\
\hline Network layouts & $\begin{array}{l}\text { Household- } \\
\text { based }\end{array}$ & $\begin{array}{l}\text { Proximate- fam- } \\
\text { ily }\end{array}$ & $\begin{array}{l}\text { Mid-range } \\
\text { family }\end{array}$ & Distant- family & $\begin{array}{l}\text { Proximate- } \\
\text { Diverse }\end{array}$ & $\begin{array}{l}\text { Expanded- } \\
\text { diverse }\end{array}$ & $\begin{array}{l}\text { Far-reaching } \\
\text { diverse }\end{array}$ \\
\hline Age in 2015 & $\begin{array}{l}-0.002 * * * \\
(0.000)\end{array}$ & $\begin{array}{l}0.004 * * * \\
(0.001)\end{array}$ & $\begin{array}{l}0.001 * \\
(0.000)\end{array}$ & $\begin{array}{l}0.000 \\
(0.000)\end{array}$ & $\begin{array}{l}0.001 \\
(0.001)\end{array}$ & $\begin{array}{l}-0.003 * * * \\
(0.000)\end{array}$ & $\begin{array}{l}-0.000 \\
(0.000)\end{array}$ \\
\hline $\begin{array}{l}\text { Female (Ref: } \\
\text { Male) }\end{array}$ & $\begin{array}{l}-0.056^{* * * *} \\
(0.006)\end{array}$ & $\begin{array}{l}-0.008 \\
(0.009)\end{array}$ & $\begin{array}{l}0.003 \\
(0.006)\end{array}$ & $\begin{array}{l}0.000 \\
(0.006)\end{array}$ & $\begin{array}{l}0.043 * * * \\
(0.009)\end{array}$ & $\begin{array}{l}0.009 \\
(0.006)\end{array}$ & $\begin{array}{l}0.009 \\
(0.005)\end{array}$ \\
\hline \multicolumn{8}{|c|}{ Education (Ref: Low) } \\
\hline Middle & $\begin{array}{l}-0.022 * * \\
(0.008)\end{array}$ & $\begin{array}{l}-0.038^{* *} \\
(0.012)\end{array}$ & $\begin{array}{l}-0.014 \\
(0.007)\end{array}$ & $\begin{array}{l}0.025^{* *} \\
(0.009)\end{array}$ & $\begin{array}{l}0.003 \\
(0.011)\end{array}$ & $\begin{array}{l}0.022 * * \\
(0.008)\end{array}$ & $\begin{array}{l}0.024 * * * \\
(0.006)\end{array}$ \\
\hline High & $\begin{array}{l}-0.017 \\
(0.009)\end{array}$ & $\begin{array}{l}-0.093 * * * \\
(0.013)\end{array}$ & $\begin{array}{l}-0.023^{* *} \\
(0.008)\end{array}$ & $\begin{array}{l}0.066^{* * * *} \\
(0.011)\end{array}$ & $\begin{array}{l}-0.011 \\
(0.013)\end{array}$ & $\begin{array}{l}0.022^{*} \\
(0.009)\end{array}$ & $\begin{array}{l}0.056^{* * *} \\
(0.008)\end{array}$ \\
\hline $\begin{array}{l}\text { Employed (Ref: } \\
\text { Not working) }\end{array}$ & $\begin{array}{l}0.007 \\
(0.010)\end{array}$ & $\begin{array}{l}-0.016 \\
(0.014)\end{array}$ & $\begin{array}{l}0.024 * \\
(0.009)\end{array}$ & $\begin{array}{l}-0.009 \\
(0.010)\end{array}$ & $\begin{array}{l}-0.011 \\
(0.013)\end{array}$ & $\begin{array}{l}0.002 \\
(0.008)\end{array}$ & $\begin{array}{l}0.003 \\
(0.007)\end{array}$ \\
\hline \multicolumn{8}{|c|}{ Financial status (Ref: Great difficulty to make ends meet) } \\
\hline Some difficulty & $\begin{array}{l}0.014 \\
(0.010)\end{array}$ & $\begin{array}{l}-0.016 \\
(0.016)\end{array}$ & $\begin{array}{l}0.006 \\
(0.010)\end{array}$ & $\begin{array}{l}0.007 \\
(0.012)\end{array}$ & $\begin{array}{l}-0.025 \\
(0.017)\end{array}$ & $\begin{array}{l}0.003 \\
(0.012)\end{array}$ & $\begin{array}{l}0.011 \\
(0.011)\end{array}$ \\
\hline Fairly easily & $\begin{array}{l}0.001 \\
(0.010)\end{array}$ & $\begin{array}{l}-0.002 \\
(0.017)\end{array}$ & $\begin{array}{l}0.014 \\
(0.010)\end{array}$ & $\begin{array}{l}0.005 \\
(0.012)\end{array}$ & $\begin{array}{l}-0.038^{*} \\
(0.017)\end{array}$ & $\begin{array}{l}0.018 \\
(0.013)\end{array}$ & $\begin{array}{l}0.002 \\
(0.010)\end{array}$ \\
\hline Easily & $\begin{array}{l}0.019 \\
(0.011)\end{array}$ & $\begin{array}{l}-0.025 \\
(0.017)\end{array}$ & $\begin{array}{l}0.016 \\
(0.011)\end{array}$ & $\begin{array}{l}0.009 \\
(0.012)\end{array}$ & $\begin{array}{l}-0.037 * \\
(0.018)\end{array}$ & $\begin{array}{l}0.015 \\
(0.013)\end{array}$ & $\begin{array}{l}0.003 \\
(0.010)\end{array}$ \\
\hline \multicolumn{8}{|c|}{ Marital status (Ref: Married) } \\
\hline Never married & $\begin{array}{l}-0.179 * * * \\
(0.010)\end{array}$ & $\begin{array}{l}0.025 \\
(0.024)\end{array}$ & $\begin{array}{l}-0.000 \\
(0.012)\end{array}$ & $\begin{array}{l}-0.026 \\
(0.019)\end{array}$ & $\begin{array}{l}0.107 * * * \\
(0.023)\end{array}$ & $\begin{array}{l}0.069 * * * \\
(0.014)\end{array}$ & $\begin{array}{l}0.004 \\
(0.009)\end{array}$ \\
\hline Divorced & $\begin{array}{l}-0.182 * * * \\
(0.008)\end{array}$ & $\begin{array}{l}-0.006 \\
(0.016)\end{array}$ & $\begin{array}{l}0.000 \\
(0.010)\end{array}$ & $\begin{array}{l}-0.011 \\
(0.011)\end{array}$ & $\begin{array}{l}0.091 * * * \\
(0.016)\end{array}$ & $\begin{array}{l}0.066^{* * *} * \\
(0.011)\end{array}$ & $\begin{array}{l}0.041 * * * \\
(0.009)\end{array}$ \\
\hline Widowed & $\begin{array}{l}-0.150 * * * \\
(0.007)\end{array}$ & $\begin{array}{l}0.063 * * * \\
(0.012)\end{array}$ & $\begin{array}{l}-0.011 \\
(0.007)\end{array}$ & $\begin{array}{l}-0.021 * * \\
(0.007)\end{array}$ & $\begin{array}{l}0.085^{* * *} \\
(0.012)\end{array}$ & $\begin{array}{l}0.025^{* *} \\
(0.009)\end{array}$ & $\begin{array}{l}0.009 \\
(0.008)\end{array}$ \\
\hline $\begin{array}{l}\text { Mobility limita- } \\
\text { tions (Ref: } \\
\text { no or minor } \\
\text { limitations) }\end{array}$ & $\begin{array}{l}0.001 \\
(0.007)\end{array}$ & $\begin{array}{l}-0.008 \\
(0.011)\end{array}$ & $\begin{array}{l}-0.000 \\
(0.007)\end{array}$ & $\begin{array}{l}-0.001 \\
(0.008)\end{array}$ & $\begin{array}{l}0.004 \\
(0.010)\end{array}$ & $\begin{array}{l}0.003 \\
(0.008)\end{array}$ & $\begin{array}{l}0.001 \\
(0.007)\end{array}$ \\
\hline $\begin{array}{l}\text { Fair or poor } \\
\text { health (Ref: } \\
\text { good health) }\end{array}$ & $\begin{array}{l}-0.021 * * \\
(0.007)\end{array}$ & $\begin{array}{l}-0.001 \\
(0.010)\end{array}$ & $\begin{array}{l}0.012 \\
(0.007)\end{array}$ & $\begin{array}{l}0.001 \\
(0.008)\end{array}$ & $\begin{array}{l}0.006 \\
(0.010)\end{array}$ & $\begin{array}{l}0.014 \\
(0.008)\end{array}$ & $\begin{array}{l}-0.010 \\
(0.005)\end{array}$ \\
\hline $\begin{array}{l}\text { Living in rural } \\
\text { areas }\end{array}$ & $\begin{array}{l}0.011 \\
(0.006)\end{array}$ & $\begin{array}{l}0.016 \\
(0.009)\end{array}$ & $\begin{array}{l}-0.011 \\
(0.006)\end{array}$ & $\begin{array}{l}0.034 * * * \\
(0.006)\end{array}$ & $\begin{array}{l}-0.022^{*} \\
(0.009)\end{array}$ & $\begin{array}{l}-0.029 * * * \\
(0.007)\end{array}$ & $\begin{array}{l}-0.000 \\
(0.005)\end{array}$ \\
\hline $\begin{array}{l}\text { Network size } \\
\text { (excluding } \\
\text { partner) }\end{array}$ & $\begin{array}{l}-0.151^{* * *} \\
(0.003)\end{array}$ & $\begin{array}{l}0.041 * * * \\
(0.003)\end{array}$ & $\begin{array}{l}0.004 * \\
(0.002)\end{array}$ & $\begin{array}{l}-0.008^{* * *} \\
(0.002)\end{array}$ & $\begin{array}{l}0.056 * * * \\
(0.002)\end{array}$ & $\begin{array}{l}0.039 * * * \\
(0.002)\end{array}$ & $\begin{array}{l}0.019 * * * \\
(0.001)\end{array}$ \\
\hline $\begin{array}{l}\text { Good computer } \\
\text { skills }\end{array}$ & $\begin{array}{l}0.007 \\
(0.008)\end{array}$ & $\begin{array}{l}-0.009 \\
(0.012)\end{array}$ & $\begin{array}{l}0.004 \\
(0.007)\end{array}$ & $\begin{array}{l}0.006 \\
(0.008)\end{array}$ & $\begin{array}{l}-0.027^{*} \\
(0.011)\end{array}$ & $\begin{array}{l}0.009 \\
(0.007)\end{array}$ & $\begin{array}{l}0.011 \\
(0.006)\end{array}$ \\
\hline Having no child & $\begin{array}{l}-0.054 * * * \\
(0.012)\end{array}$ & $\begin{array}{l}-0.056^{* *} \\
(0.018)\end{array}$ & $\begin{array}{l}-0.033^{* * * *} \\
(0.008)\end{array}$ & $\begin{array}{l}-0.009 \\
(0.018)\end{array}$ & $\begin{array}{l}0.074 * * * \\
(0.018)\end{array}$ & $\begin{array}{l}0.038 * * \\
(0.012)\end{array}$ & $\begin{array}{l}0.040 * * * \\
(0.011)\end{array}$ \\
\hline $\begin{array}{l}\text { Any organized } \\
\text { activity }\end{array}$ & $\begin{array}{l}-0.017 * * \\
(0.006)\end{array}$ & $\begin{array}{l}-0.041 * * * \\
(0.010)\end{array}$ & $\begin{array}{l}-0.009 \\
(0.006)\end{array}$ & $\begin{array}{l}-0.005 \\
(0.006)\end{array}$ & $\begin{array}{l}0.036^{* * * *} \\
(0.010)\end{array}$ & $\begin{array}{l}0.030 * * * \\
(0.007)\end{array}$ & $\begin{array}{l}0.007 \\
(0.005)\end{array}$ \\
\hline $\begin{array}{l}\text { Having young } \\
\text { grand child }\end{array}$ & $\begin{array}{l}-0.022 * * * \\
(0.006)\end{array}$ & $\begin{array}{l}0.053 * * * \\
(0.011)\end{array}$ & $\begin{array}{l}0.017 * \\
(0.007)\end{array}$ & $\begin{array}{l}0.005 \\
(0.007)\end{array}$ & $\begin{array}{l}-0.028 * * \\
(0.010)\end{array}$ & $\begin{array}{l}-0.018^{* *} \\
(0.007)\end{array}$ & $\begin{array}{l}-0.008 \\
(0.006)\end{array}$ \\
\hline
\end{tabular}

Presenting average marginal effects. Standard errors in parentheses. $N=35,003$. We also controlled for countries where the coefficients are omitted from the table. $* p<.05 . * * p<.01 . * * * p<.001$

nearby (25.23\% of the sample). It is noteworthy that these networks are not necessarily geographically confined. Many people also listed family connections at longer distances
(23\% also have family connections between 5 and $25 \mathrm{~km}$, and $22 \%$ named family connections over $25 \mathrm{~km}$ ). Individuals in this group are especially likely to report having low 
education, being widowed, and having a young grandchild; individuals with proximate-family networks are relatively unlikely to be childless or participate in organized activities.

The third layout is mid-range family networks, in which one or more family connections lived at mid-range (5-25 km away; $9.8 \%$ of the sample). AME estimates suggest that highly educated individuals and those without children are relatively unlikely to fall into this group. Meanwhile, people currently working and having young grandchildren are somewhat likely to have such networks. We name the fourth layout distant-family networks, which features family connections at longer ranges ( $>25 \mathrm{~km}$ away; $8.87 \%$ of the sample). People in this group tended to have mid- or high education, dwell in rural areas, and not be widowed. A similarity of the third and fourth classes is limited external connections within closer proximity (within five- and twenty-five-kilometer radius, respectively, $<10 \%$ ), regardless of families or non-kins.

The remaining three geographic layouts are diverse ones featuring non-kin connections located at variant distances. We name the fifth group proximate-diverse networks, highlighting the presence of at least one non-kin confidant within the $5 \mathrm{~km}$ radius (20.76\% of the sample). Only $32.3 \%$ of individuals in such a network mentioned having a discussant in the same household, the lowest among the identified layouts. Individuals also tend to name other family discussants at variant distances. Table 2 shows that women, unmarried, childless, and active participants in organized activities are especially likely to possess proximate-diverse networks. Meanwhile, rural residents and those with good computer skills, free from financial difficulties, and having young grandchildren are relatively unlikely to have such networks.

We call the sixth group expanded-diverse networks, in which older adults mentioned one or more non-kin connections between 5 and $25 \mathrm{~km}$ (11.49\% of the sample). Older adults in expanded-diverse networks are also likely to list family discussants at varying distances, plus having a nonkin connection in proximity as well (38\%). Those occupying this group are disproportionately highly educated, active in organized activities, unmarried, and childless. Meanwhile, individuals living in a rural area or having a young grandchild are less likely to be in this group.

Finally, we identify the seventh group as far-reachingdiverse networks. Compared to groups 5 and 6 , respondents in such networks have non-kin connections living at longer distances $(>25 \mathrm{~km})$ with relatively limited family connectivity nearby $(18.2 \%$ have one within $5 \mathrm{~km}$ and $12.5 \%$ have one in the $5-25 \mathrm{~km}$ range). Still, they often have a family network member in their household (44.2\%) and non-kin connections in proximity $(31 \%)$. It is the smallest group of all geographic layouts ( $<6 \%$ of the total sample), and people in this group tend to be highly educated but disproportionately childless

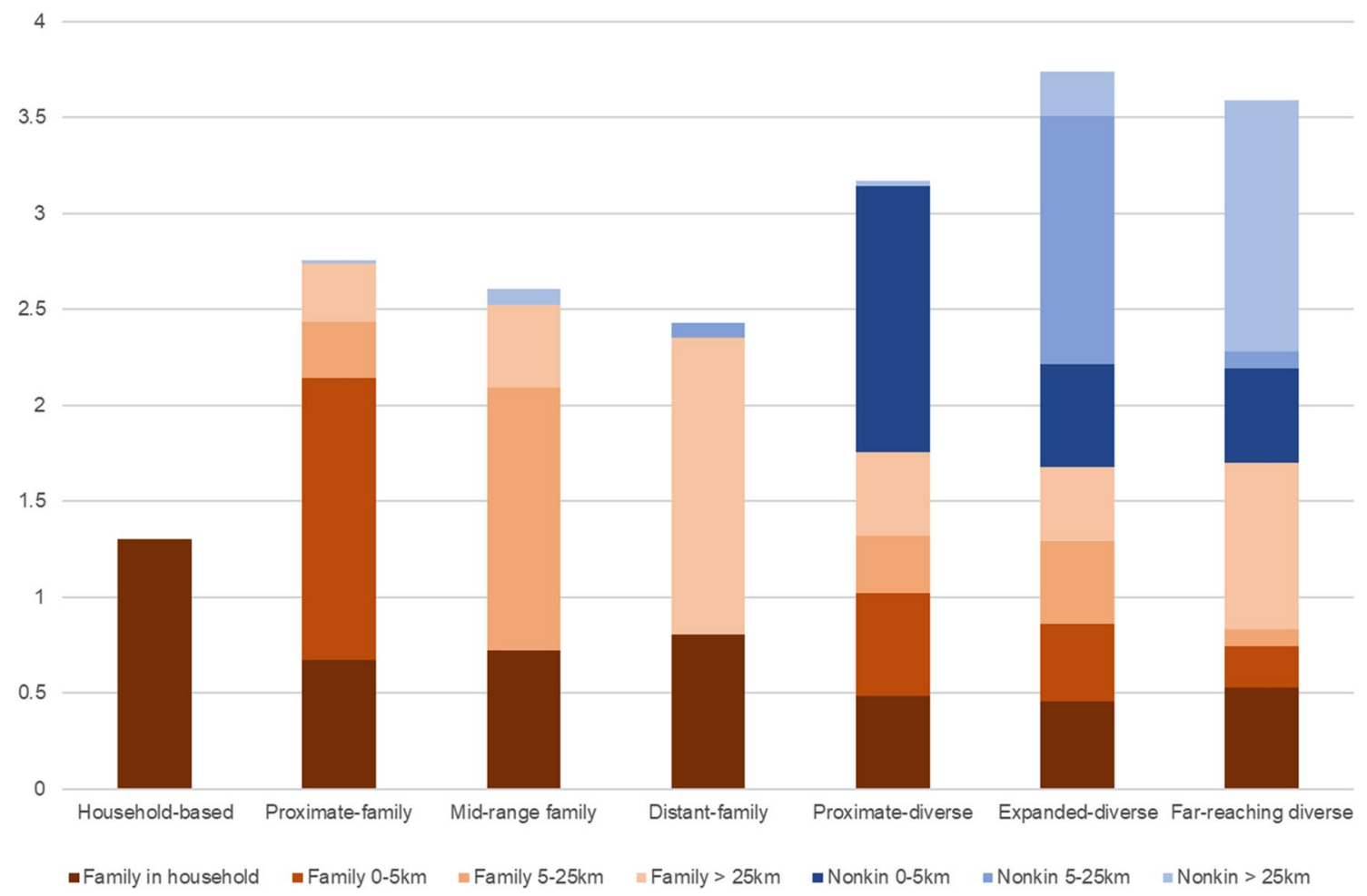

Fig. 1 The average number of family and non-kin connections at each distance, in each latent class 
or divorced. We present the composition of each geographic layout in Fig. 1.

\section{Distribution across European countries}

We compared the typical network compositions across European countries, sorting them based on the total proportion of family-oriented network layouts (groups 1-4) from the highest to the lowest in Fig. 2 (tables with the proportions in numbers are available in Appendix Table 4). Overall, familyoriented network layouts are more prevalent in Southern and Eastern European countries, consistent with the north-south division identified in the existing literature. More specifically, older adults are especially likely to have householdbased networks or proximate-family networks in Eastern and Southern European countries (all with a combined proportion $>50 \%$ ), the only exception being Estonia $(36.48 \%$ combined). Regional differences in the more proximate-family network layouts are more pronounced than mid-range and distant-family networks.

When it comes to diverse network layouts featuring nonkin members, findings reveal that expanded- and far-reaching-diverse networks drive regional differences more so than proximate-diverse networks. For instance, proximate-diverse networks are relatively prevalent in several Southern (Spain, Portugal, and Greece) and Eastern (Croatia, Slovenia, and Czech Republic) countries, exceeding Denmark and Sweden from the north and Central countries such as Germany and Switzerland. In contrast, the division between Northern/Central and Eastern/Southern countries is evident in expandedand far-reaching-diverse networks, both of which are more prevalent in the former set of regions (ranging from 30.03\% combined in Belgium to $20.92 \%$ in Luxembourg) than the latter one (ranging from $16.02 \%$ in Estonia to $3.24 \%$ in Poland).

\section{Network layouts, function, and quality}

Figure $3 \mathrm{a}, \mathrm{b}, \mathrm{c}, \mathrm{d}$ showcases the result from the OLS regressions on the association between socio-geographic layouts and network function and quality, adjusting for all the covariates we have used in the present research. To avoid arbitrarily selecting one network layout as the reference group and the basis of comparison, we compare the predicted value of each group with the dependent variable's grand mean to depict how variation in network function/ quality is a function of geographic layout (Mitchell 2021). Not surprisingly, as shown in Fig. 3a, household-based networks and proximate-family networks offer the highest level of network contact ( 0.11 and 0.14 SD higher than the overall average, respectively), followed by proximatediverse networks (0.06 SD higher than average). While individuals' contact with their mid-range and distant-family

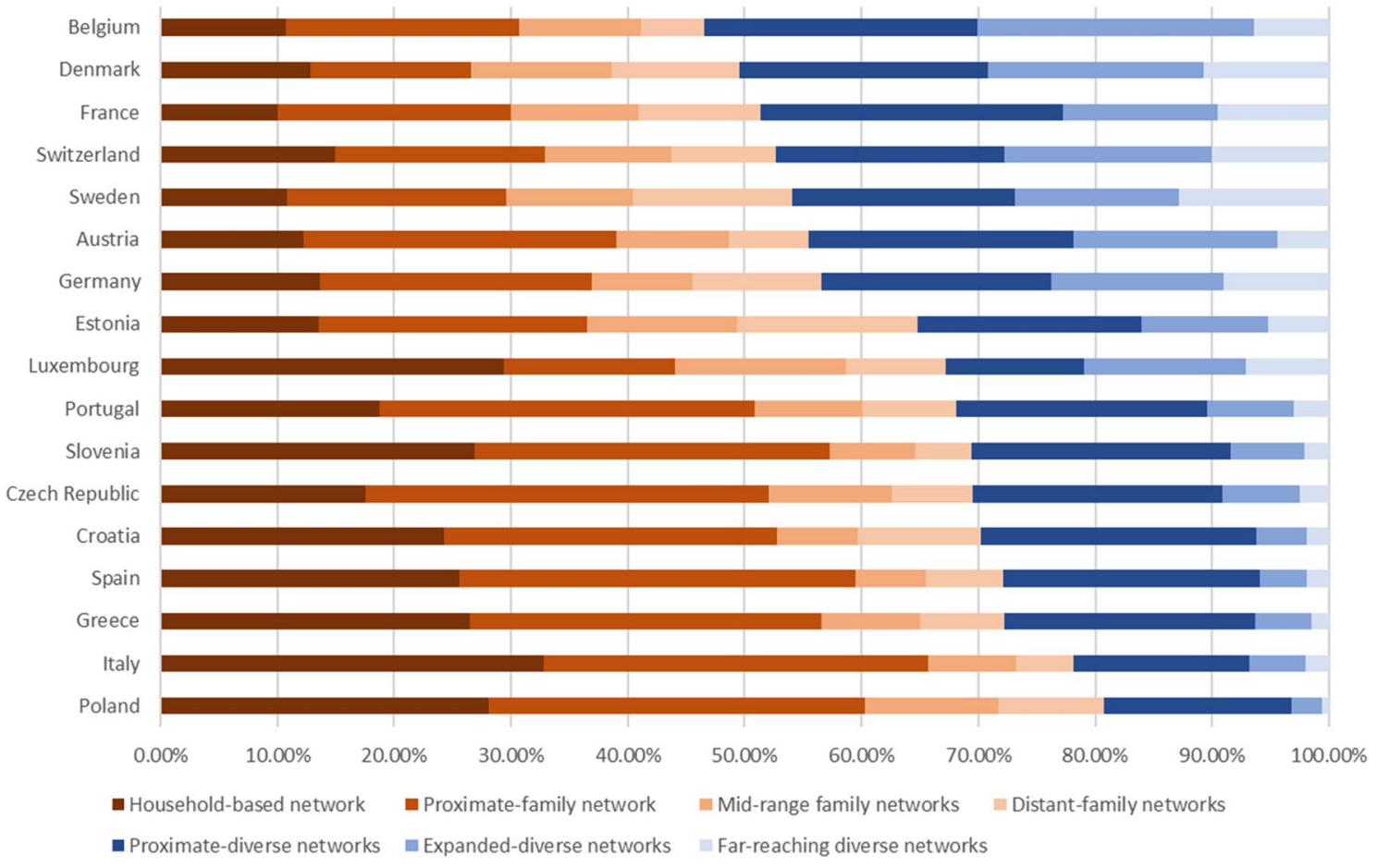

Fig. 2 Core network geographic layouts in each country. Note: countries sorted by the total proportion of family-oriented network layouts (i.e., the sum of household-based network, proximate-family network, mid-range family network, and distant-family network) 

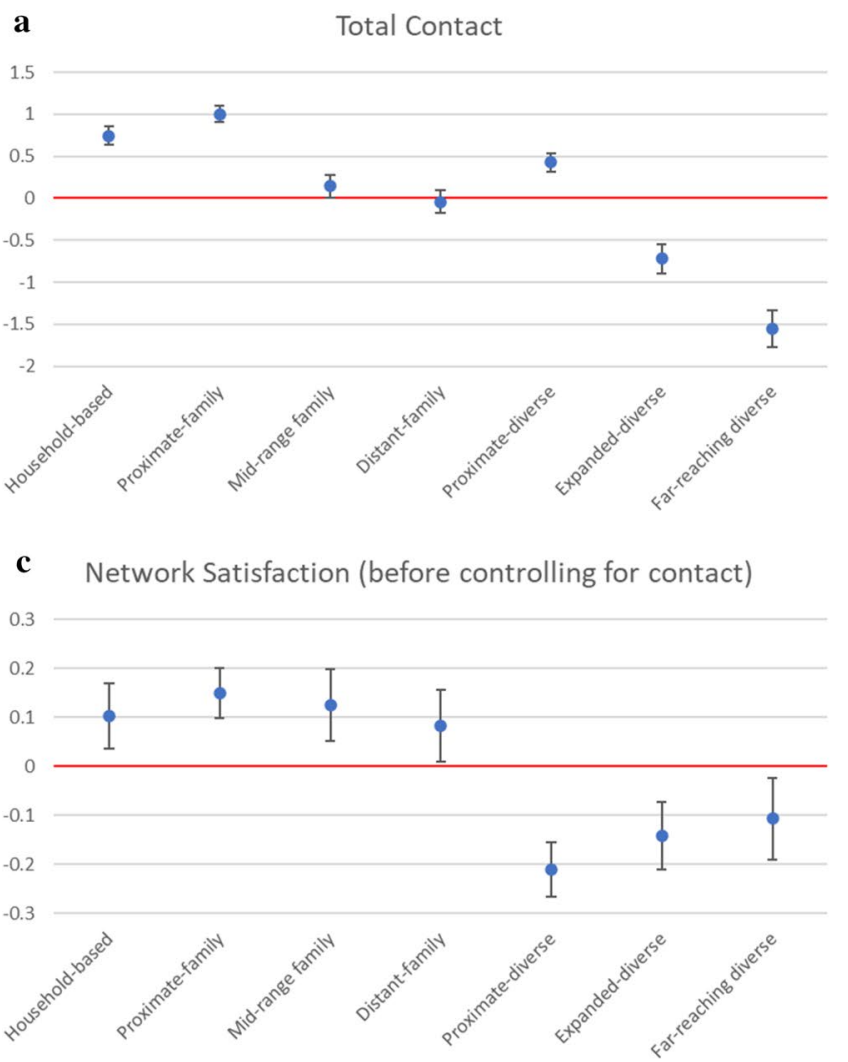

Fig. 3 Results from the regressions of contact with network members, average emotional closeness with network members, and overall network satisfaction. Notes: Results for each network layout are presented as average adjusted predictions (AAPs). The red lines represent the overall average of the corresponding dependent variable. The model's control variables include age, gender, education, employ-

networks is close to the overall average, their counterparts in expanded- and far-reaching-diverse networks have the lowest estimated amount of network contact ( 0.10 and 0.22 SD lower than average).

Frequent contact with network connections, however, does not necessarily translate to high levels of emotional closeness. As Fig. 3b shows, respondents express higher emotional closeness with family-oriented networks than diverse networks featuring non-kin discussants, regardless of proximity. In addition, the emotional closeness with network members is not always lower in more geographically expanded network layouts. Indeed, older adults' emotional closeness with members in distant-family networks is comparable to their counterparts who have proximate-family networks. Such a pattern similarly applies to diverse networks, where far-reaching-diverse networks feature higher emotional closeness than the proximate- and expandeddiverse networks. Additional analysis further confirms that these patterns still hold even after controlling for different levels of contact with network members (results available upon request).
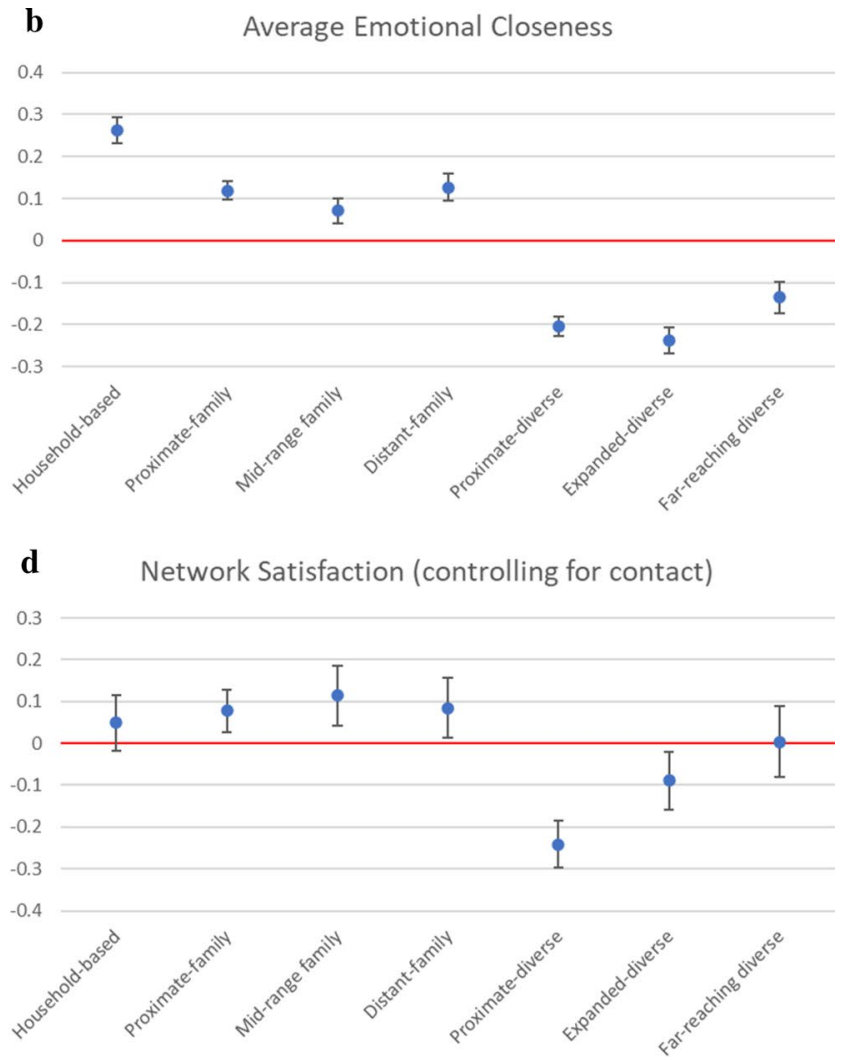

ment, financial status, marital status, functional limitations, self-rated health, rural vs. urban context, network size (excluding partner), computer skills, having no children, organized activity participation, grandparent status. The model presented in Fig. 3d also controlled for average contact

Lastly, we turn to an overall evaluation of network satisfaction. Figure $3 \mathrm{c}$ shows that the family-centered layouts are not statistically distinguishable from one another on this variable, as evidenced by the overlapping confidence intervals. All four family-oriented network layouts feature network satisfaction above the overall average. In contrast, satisfaction with diverse networks is significantly lower than the average in all three geographic layouts. Additional analysis shows that the pattern persists even if confining the sample to northern/central European countries or their southern/eastern counterparts.

One concern of the network satisfaction estimates is that differences in contact frequency depending on geographic layout may suppress the patterns depicted in Fig. 3c. That is, frequent contact with network members boosts network satisfaction (as confirmed in a supplementary analysis), so the convenience of seeing nearby network members could distort some meaningful variation in satisfaction across geographic layouts. A suppression pattern does not seem to apply to family-oriented networks; differences across geographic distance remain virtually unchanged in the model 
that adjusts for contact frequency (Fig. 3d) from the model that does not (Fig. 3c). Result suggests that people tend to be relatively satisfied with networks composed mainly of family members, regardless of whether they are immediately accessible or not. For the compositionally diverse networks, however, there does seem to be a suppressive pattern. Once network contact is adjusted, gaps between proximate-diverse and expanded/far-reaching diverse groups widen, the former group becoming significantly different from the latter two. Far-reaching-diverse networks align with the overall average of network satisfaction, becoming statistically indistinguishable from the family networks (groups 1-4).

\section{Discussion}

Intimate and supportive network connections are critical contributors to the well-being of older people (e.g., Ha and Carr 2005; Spring et al. 2017; Cornwell and Goldman 2021). As older adults' networks have become increasingly diverse (Goldman and Cornwell 2018; Harper et al. 2020), there are rising concerns about the absence of proximal connections and the consequences on older adults' social life and well-being (e.g., Hank 2007; Fihel et al. 2021). The present research addresses these concerns by establishing a new geographic-focused typology of older adults' core discussion networks. The new approach identifies typical geographic layouts of older Europeans' core discussion networks, revealing unique diversities unacknowledged in existing network typologies. It also provides a new perspective on how different network structures link to function and quality.

The present geographic-focused typology reveals spatial diversities in family-focused networks, one predominant network form identified in previous research (e.g., Fiori et al. 2006; Litwin and Stoeckel 2013). Our typology reveals household-based, proximate-, mid-range, and distant-family networks. Existing typologies characterize those in restricted and family-centered networks as at advanced ages, unmarried, and have lower incomes and more physical limitations (Litwin 2001, 2003, 2009; Fiori et al. 2006, 2007, 2008; Fiori and Jager 2012; Djundeva et al. 2019). However, to our surprise, discussion networks limited to the household are not necessarily a sign of frailty or disadvantage, as adults occupying them tend to be younger, married, in good health, and having one or more children.

In our typology, disadvantage and marginalization are more apparent among older adults in what we term proximate-family networks. Adults with these network forms tend to be at advanced ages, have lower education, and be widowed. These observations correspond to the depiction of older adults in high need of ready support, many of whom have relocated for family accessibility reasons (Logan and Spitze 1994; Spring et al. 2017; Cornwell and Goldman
2021). Moreover, individuals in proximate-family networks also often mention family discussants in intermediate or even longer distances. Future research needs to pay more attention to the roles of these non-proximate-family discussants, especially how they coordinate with the more proximate ones.

Further attesting to diversity in family-focused networks, our geographic-focused typology also identifies mid-range and distant-family networks. Analogous to the empty-nest metaphor, these layouts present an "empty neighborhood" scenario where people have few families or non-kin discussants readily accessible yet sustain family discussants at a distance (over $5 \mathrm{~km}$ or beyond $25 \mathrm{~km}$ in our typology). Results show that a sizable group of older adults hold on to a spatially scattered assemblage of family member discussants rather than enlisting non-kin discussants as alternatives (e.g., Mair and Carr 2019; Fihel et al. 2021). Such distantfamily networks are most prevalent among older adults with high educational backgrounds and those living in rural areas. Individuals with higher education may have higher mobility in their life courses (Viry 2012), and the younger generations may live away from their rural hometowns (Rérat 2014; Lovén et al. 2020). This observation adds nuance to previous findings that more educated individuals possess more diverse networks (e.g., Litwin 2001; Fiori et al. 2006, 2008). It turns out many still prefer to keep their discussant network within the family and are more accommodating with an expanded geographic layout.

Emphasizing the proximity perspective in family-oriented network types also reveals the nuance in regional patterns. As anticipated, the four family network types combined are more prevalent in the Southern and Eastern European countries, likely attributable to their familistic culture and limited welfare provision (Reher 1998; Litwin 2009; Litwin and Stoeckel 2013; Dykstra 2018). The present research also shows that older adults who occupy family-oriented networks in the more individualistic northern and western countries disproportionately embrace the "empty neighborhood" scenario and maintain family discussants at longer distances. This finding suggests that the "intimacy at a distance" (Rosenmayr and Köckeis 1963) between family members can stretch over relatively long distances, especially in the more individualistic countries.

Our geographic-focused typology also expands the notion of "diverse networks", which in existing research emphasizes compositional-but not spatial-forms of diversity (e.g., Fiori et al. 2006; Park et al. 2014; Szabo et al. 2016). We identify proximate-, expanded-, and far-reaching-diverse networks. Our findings depart from studies that bind diverse networks with advantaged statuses, such as younger age, higher educational background, higher income, engagement in community activities, and good functional capabilities (Wenger et al. 1996; Litwin 2001; Fiori et al. 2006, 2008; 
Fiori and Jager 2012; Cornwell and Goldman 2021). Our findings suggest that compositionally diverse networks are more likely a sign of advantage only when complemented by flexible spatial arrangements. Indeed, high levels of education are associated with occupying expanded- and far-reaching-diverse networks, not proximate-diverse networks. Likewise, being free of financial hardship predicts a lower likelihood of being found in a proximate-diverse network form. This observation echoes recent findings that local non-kin ties could be more prevalent in high-poverty neighborhoods (York Cornwell \& Goldman 2021). Listing only non-kin discussants in proximity could be attributed to their mere accessibility for general support rather than their knowledge, skills, trustworthiness, or intimacy (Small and Sukhu 2016).

Examining compositionally diverse networks through the lens of geographic layout also extends our understanding of their regional patterns (Litwin and Stoeckel 2013; Djundeva et al. 2019). Our findings indicate that proximate-diverse networks vary little across the Europe and are prevalent across all regions. Individuals may list accessible non-kin discussants to fulfill the imminent needs for practical support or compensate for insufficient family support (Litwin and Stoeckel 2013; Small 2013; Small and Sukhu 2016; Fihel et al. 2021). Indeed, it seems that the overrepresentation of diverse networks in Northern and Central European countries owes primarily to the higher prevalence of expanded- and far-reaching-diverse networks. It is possible that in the more individualistic and high-trust northern and central European countries (Reher 1998; Letki 2017; Inglehart 2020), individuals are particularly open to non-intimate yet knowledgeable discussants that fit their needs (Small 2013), sustaining many of them beyond proximity.

The present research also evaluates the implications of the variant geographic layouts of older adults' core discussion networks. One of the key takeaways is that the structural feature of distance has little association with several important aspects of overall network function and quality, particularly emotional closeness and satisfaction. Unsurprisingly, people talk more to their network when it is nearby. Family-centered networks have the most contact, yet a diverse network close-by features more frequent contact than one filled with kin members far away. There is also an expected gap between kin-based and diverse networks regarding emotional closeness. Still, there is no evidence that emotional closeness trails off when network members are farther away within each of these relational categories. As for the nonlinear association of distance and emotional closeness suggested within family and diverse network groupings, the pattern may reflect selectivity. That is, the reason that farther-off network members are in the network in the first place-despite fewer chances for interaction-is that these people are emotionally significant.
Further, once contact frequency factors into the analysis, we cannot statistically distinguish the network satisfaction for far-reaching-diverse networks from the family-centered forms. For network satisfaction, the arrangement that stands most clearly apart from all others is the proximate-diverse networks, which include close-by non-kin members, frequently alongside family member(s) at varying distances. The high average levels of interaction shared with such networks may obscure that the encounters are often more a function of convenience than choice. Network satisfaction skews toward high contentment, so this should not be interpreted to mean that people are dissatisfied with networks that cluster nearby. Nevertheless, results suggest that if it were not because proximate network members are most accessible, there would be a relatively wide gap in network satisfaction between the $20 \%$ of older adults in proximatediverse networks and those with other networks. Close-by non-kin can meet many social support and companionship needs (York Cornwell and Goldman, 2021), but proximity does not by itself confer a higher satisfaction.

The present study has some limitations. As we used latent class analysis to identify the typical network compositions among older Europeans, the present study was cross-sectional and descriptive. It is a starting point to trace how network members' proximity may change along the aging process and how it might matter for outcomes such as social support provision and well-being. Consistent with the crosssectional design, we are not making causal arguments about how individual characteristics produce a given network type. Instead, we see our efforts as describing which older adults fall into which type of network and providing a preliminary answer to how each network type links to a set of fundamental aspects of network function and quality.

We also acknowledge that we cannot specify the type of support one receives from each connection, especially when they source from variant distances. The proximate connections are often better positioned to provide the support that requires physical co-presence, such as personal care, transportation, household help, assistance with paperwork, and other instrumental help (Hank 2007; Cornwell and Goldman 2021; Fihel et al. 2021). Meanwhile, connections at longer distances have also become more capable of providing companionship, emotional support, advice, and service arrangements, thanks to the new communication technologies (Quan-Haase et al. 2017; Harper et al. 2020). Future research with more comprehensive network data should further identify the patterns in who provides what support at varying distances.

Finally, our choice of thresholds in grouping a connections' proximity is somewhat arbitrary. Part of this results from the design of the SHARE data, which measures confidants' proximity in categories without fine-grained cut points between 25 and $100 \mathrm{~km}$. In addition, the perception 
of proximity could vary across individuals, urban/rural regions, and countries across Europe. That said, $25 \mathrm{~km}$ often represents the distance traversable within an hour's drive, a metropolitan area covered by public transit, or a visit that requires little planning. In addition, parents who do not have a child within $25 \mathrm{~km}$ are more likely to incorporate non-family support (Fihel et al. 2021). Future research on network typologies would benefit from more detailed proximity measures.

\section{Conclusion}

In sum, the present research addressed a gap in the literature by revealing how older adults combine family members and non-relatives at different proximity in their networks, a phenomenon not yet fully recognized by existing typologies. It highlighted the importance of looking beyond the mere presence of proximate connections in older adults' close social networks. In the emerging context of networked individualism, where there are more options than ever for keeping in touch, physical proximity still matters in core discussion networks. Though proximity fosters contact, more scattered network layouts and longer distances are not insurmountable obstacles to network satisfaction, especially with sufficient contact with the members-a condition becoming ever more realizable through technology advances. We also found that proximate-diverse networks are common among older Europeans, even in countries considered to be most familyoriented. Such a layout provided interactions comparable in frequency to networks primarily consisting of nearby family members, even if somewhat lower in overall network satisfaction. Especially in light of the many disruptions caused by the COVID-19 pandemic and the possibility of future stay-at-home orders, researchers must keep an eye on the changing spatial configurations of older adults' core networks and the implications of these developments for their social connectedness and well-being.

\section{Appendix 1}

This section describes the operationalization and measurement of covariates included in multinomial regression predicting geographic layout classes and in regression analysis of network contact, emotional closeness, and satisfaction.

Starting with SES-related factors, we regroup older adults' educational background from the 7-level ISCED97 criteria to three categories, including $1=$ low education (including up to lower secondary education/compulsory education); $2=$ medium education (including upper secondary and post-secondary non-tertiary education); $3=$ high education (including the first stage of tertiary education and second stage of tertiary education). We measure employment status as a dichotomous variable, coding currently employed or self-employed as 1 and 0 otherwise. A self-evaluation measured an individual's household financial standing: "thinking of your household's total monthly income, would you say that your household is able to make ends meet?" The answer ranges from 1 to 4 , where $1=$ with great difficulty; 2 = with some difficulty; 3 =fairly easily; $4=$ easily. This financial standing measure evaluates perceived financial strain regardless of diverse income sources and welfare availabilities.

We also consider other individual resources that facilitate interaction and general aspects of social connectedness. We code respondents' self-reported computer skills as 1 for an excellent, very good, or good rating, and as 0 for fair and poor ratings, or never used a computer. One's network size is a count measure of up to seven network members. We identify any participation in organized social activities as 1 and 0 otherwise, which includes "doing voluntary or charity work," "attending an educational or training course," "going to a sport, social or other kinds of clubs," and "taking part in a political or communityrelated organization."

We also consider several social demographic backgrounds and health statuses that may affect one's network layout. Respondents' age (in years) in 2015 is a continuous variable. We code gender as $0=$ male and $1=$ female. Marital statuses include married, never married, divorced, and widowed. We label childless individuals as 1 , otherwise 0 .

Regarding self-rated health, we group excellent, very good, and good health as 0 , which serves as the reference group, and fair or poor health as 1 . We code mobility limitation as 1 for older adults reporting three or more instances of mobility, arm function, and fine motor limitations, and as 0 otherwise. We identify grandparents who have a young grandchild under five years old as 1 and otherwise 0 . Regarding the level of urbanization in the area of a respondent's residence, we consider a big city, suburbs of a big city, or a large town as more urbanized areas $=0$, and a small town, a rural area, or a village as less urbanized areas $=1$.

See Tables 3, 4, 5, 6 . 
Table 3 Model fit indicators for LCA, 1-8 classes

Table 4 Average latent class probabilities for most likely class membership (in rows) by other latent classes (in columns)

\begin{tabular}{llllllll}
\hline \# of Classes & AIC & BIC & SSA-BIC & Entropy & VLMR & LMR & $\begin{array}{l}\text { BLRT- } p \\
\text { value }\end{array}$ \\
\hline 1 & $282,872.7$ & 283,001 & $282,953.3$ & 0.583 & 0 & 0 & 0 \\
2 & $280,192.3$ & 280,389 & $280,315.9$ & 0.615 & 0 & 0 & 0 \\
3 & $279,148.1$ & $279,413.3$ & $279,314.8$ & 0.715 & 0 & 0 & 0 \\
4 & $278,193.9$ & $278,527.6$ & $278,403.6$ & 0.711 & 0 & 0 & 0 \\
5 & $277,237.7$ & $277,639.8$ & $277,490.4$ & 0.718 & 0 & 0 & 0 \\
6 & $276,692.5$ & 277,163 & $276,988.2$ & 0.814 & 0 & 0 & 0 \\
7 & $276,682.5$ & $277,221.5$ & $277,021.2$ & 0.76 & 0 & 0 & 0 \\
8 & $282,872.7$ & 283,001 & $282,953.3$ & 0.583 & 0 & 0 & 0 \\
\hline
\end{tabular}

\begin{tabular}{llllllll}
\hline & \multicolumn{7}{l}{ Probability to be $\ldots$} \\
\cline { 2 - 7 } & Class 1 & Class 2 & Class 3 & Class 4 & Class 5 & Class 6 & Class 7 \\
\hline Identified as Class 1 & 0.705 & 0.065 & 0.046 & 0.028 & 0.054 & 0.048 & 0.053 \\
Identified as Class 2 & 0.000 & 0.753 & 0.106 & 0.051 & 0.069 & 0.007 & 0.014 \\
Identified as Class 3 & 0.000 & 0.000 & 0.825 & 0.038 & 0.105 & 0.005 & 0.027 \\
Identified as Class 4 & 0.027 & 0.000 & 0.000 & 0.973 & 0.000 & 0.000 & 0.000 \\
Identified as Class 5 & 0.000 & 0.000 & 0.000 & 0.000 & 1.000 & 0.000 & 0.000 \\
Identified as Class 6 & 0.031 & 0.101 & 0.043 & 0.049 & 0.045 & 0.714 & 0.016 \\
Identified as Class 7 & 0.000 & 0.000 & 0.000 & 0.061 & 0.088 & 0.023 & 0.828 \\
\hline
\end{tabular}

The average of predicted probabilities for each latent class on the diagonal 
Table 5 Descriptive statistics of the respondents

\begin{tabular}{|c|c|c|}
\hline Descriptive statistics & Mean/\% & SD \\
\hline Overall network contact scale & 13.33 & 6.93 \\
\hline Average closeness with network members & 3.29 & 0.59 \\
\hline Network satisfaction & 9 & 1.19 \\
\hline Age in 2015 & 68.52 & 9.67 \\
\hline \multicolumn{3}{|l|}{ Gender } \\
\hline Male & $39.90 \%$ & \\
\hline Female & $60.10 \%$ & \\
\hline \multicolumn{3}{|l|}{ Education } \\
\hline Low & $39.97 \%$ & \\
\hline Middle & $37.57 \%$ & \\
\hline High & $22.46 \%$ & \\
\hline \multicolumn{3}{|l|}{ Employment status } \\
\hline Not working & $77.66 \%$ & \\
\hline Employed & $22.34 \%$ & \\
\hline \multicolumn{3}{|l|}{ Financial status } \\
\hline No difficulty & $35.21 \%$ & \\
\hline Little difficulty & $27.01 \%$ & \\
\hline Some difficulty & $25.78 \%$ & \\
\hline Much difficulty & $12.01 \%$ & \\
\hline \multicolumn{3}{|l|}{ Marital status } \\
\hline Married & $62.67 \%$ & \\
\hline Never married & $6.50 \%$ & \\
\hline Divorced & $11.01 \%$ & \\
\hline Widowed & $19.81 \%$ & \\
\hline \multicolumn{3}{|l|}{ Mobility limitations } \\
\hline No or little limitations $(0-2)$ & $73.61 \%$ & \\
\hline Multiple limitations (3 or more) & $26.39 \%$ & \\
\hline \multicolumn{3}{|l|}{ Self-rated health } \\
\hline Excellent, very good or good health & $60.73 \%$ & \\
\hline Fair or poor health & $39.27 \%$ & \\
\hline \multicolumn{3}{|l|}{ Living circumstances } \\
\hline Non-rural & $41.86 \%$ & \\
\hline Rural & $58.14 \%$ & \\
\hline Core network size (excluding partner) & 2.71 & 1.5 \\
\hline \multicolumn{3}{|l|}{ Computer skills } \\
\hline Limited skills & $70.15 \%$ & \\
\hline Good skills & $29.85 \%$ & \\
\hline \multicolumn{3}{|l|}{ Child status } \\
\hline Having one or more child & $89.82 \%$ & \\
\hline Having no child & $10.18 \%$ & \\
\hline \multicolumn{3}{|l|}{ Organized activity } \\
\hline No activity & $65.54 \%$ & \\
\hline One or more activities & $34.46 \%$ & \\
\hline \multicolumn{3}{|l|}{ Grandchild status } \\
\hline Not having young grandchild & $77.30 \%$ & \\
\hline Having young grandchild & $22.70 \%$ & \\
\hline
\end{tabular}


Table 6 Core network geographic layouts in each country

Household-based Proximate- family Mid-range family Distant- family Proximate- Diverse Expanded-diverse Far-reach-

ing diverse

\begin{tabular}{|c|c|c|c|c|c|c|c|}
\hline Belgium & $10.70 \%$ & $19.97 \%$ & $10.50 \%$ & $5.35 \%$ & $23.44 \%$ & $23.58 \%$ & $6.45 \%$ \\
\hline Denmark & $12.89 \%$ & $13.71 \%$ & $11.99 \%$ & $11.00 \%$ & $21.24 \%$ & $18.49 \%$ & $10.69 \%$ \\
\hline France & $10.04 \%$ & $20.00 \%$ & $10.93 \%$ & $10.44 \%$ & $25.87 \%$ & $13.20 \%$ & $9.51 \%$ \\
\hline Switzerland & $14.96 \%$ & $17.92 \%$ & $10.81 \%$ & $8.93 \%$ & $19.57 \%$ & $17.75 \%$ & $10.07 \%$ \\
\hline Sweden & $10.83 \%$ & $18.77 \%$ & $10.79 \%$ & $13.72 \%$ & $19.03 \%$ & $14.07 \%$ & $12.78 \%$ \\
\hline Austria & $12.26 \%$ & $26.76 \%$ & $9.62 \%$ & $6.79 \%$ & $22.71 \%$ & $17.43 \%$ & $4.44 \%$ \\
\hline Germany & $13.69 \%$ & $23.27 \%$ & $8.60 \%$ & $11.01 \%$ & $19.65 \%$ & $14.79 \%$ & $8.98 \%$ \\
\hline Estonia & $13.57 \%$ & $22.91 \%$ & $12.92 \%$ & $15.40 \%$ & $19.19 \%$ & $10.82 \%$ & $5.20 \%$ \\
\hline Luxembourg & $29.42 \%$ & $14.61 \%$ & $14.61 \%$ & $8.60 \%$ & $11.84 \%$ & $13.85 \%$ & $7.07 \%$ \\
\hline Portugal & $18.81 \%$ & $32.02 \%$ & $9.28 \%$ & $8.01 \%$ & $21.47 \%$ & $7.37 \%$ & $3.05 \%$ \\
\hline Slovenia & $26.93 \%$ & $30.34 \%$ & $7.35 \%$ & $4.75 \%$ & $22.24 \%$ & $6.31 \%$ & $2.08 \%$ \\
\hline Czech Rep & $17.58 \%$ & $34.51 \%$ & $10.52 \%$ & $6.95 \%$ & $21.34 \%$ & $6.64 \%$ & $2.46 \%$ \\
\hline Croatia & $24.26 \%$ & $28.48 \%$ & $6.96 \%$ & $10.55 \%$ & $23.56 \%$ & $4.29 \%$ & $1.90 \%$ \\
\hline Spain & $25.59 \%$ & $33.93 \%$ & $6.03 \%$ & $6.56 \%$ & $21.99 \%$ & $3.98 \%$ & $1.93 \%$ \\
\hline Greece & $26.45 \%$ & $30.14 \%$ & $8.45 \%$ & $7.23 \%$ & $21.45 \%$ & $4.83 \%$ & $1.46 \%$ \\
\hline Italy & $32.81 \%$ & $32.86 \%$ & $7.54 \%$ & $4.96 \%$ & $14.97 \%$ & $4.86 \%$ & $1.99 \%$ \\
\hline Poland & $28.11 \%$ & $32.20 \%$ & $11.44 \%$ & $9.04 \%$ & $15.96 \%$ & $2.68 \%$ & $0.56 \%$ \\
\hline
\end{tabular}

Countries sorted by the total proportion of family-oriented network layouts (i.e., the sum of household-based network, proximate-family network, mid-range family network, and distant-family network)

Acknowledgements This paper uses data from SHARE Waves 1, 2, 3, 4, 5, 6, 7, and 8, see Börsch-Supan et al. (2013) for methodological details. The SHARE data collection has been funded by the European Commission through FP5 (QLK6-CT-2001-00360), FP6 (SHARE-I3: RII-CT-2006-062193, COMPARE: CIT5-CT-2005-028857, SHARELIFE: CIT4-CT-2006-028812), FP7 (SHARE-PREP: GA N²11909, SHARE-LEAP: GA N²27822, SHARE M4: GA N²61982, DASISH: GA N²83646), and Horizon 2020 (SHARE-DEV3: GA N676536, SHARE-COHESION: GA N ${ }^{\circ} 870628$, SERISS: GA N ${ }^{\circ} 654221$, SSHOC: GA N ${ }^{\circ} 823782$ ) and by DG Employment, Social Affairs \& Inclusion. Additional funding from the German Ministry of Education and Research, the Max Planck Society for the Advancement of Science, the US National Institute on Aging (U01_AG09740-13S2, P01_ AG005842, P01_AG08291, P30_AG12815, R21_AG025169, Y1-AG4553-01, IAG_BSR06-11, OGHA_04-064, HHSN271201300071C) and from various national funding sources is gratefully acknowledged (see www.share-project.org).

Funding No funding was received to assist with the preparation of this manuscript. The authors have no relevant financial or non-financial interests to disclose.

\section{References}

Aartsen MJ, van Tilburg T, Smits CHM, Knipscheer KCPM (2004) A longitudinal study of the impact of physical and cognitive decline on the personal network in old age. J Soc Pers Relat 21:249-266. https://doi.org/10.1177/0265407504041386

Antonucci TC, Akiyama H (1995) Convoys of social relations: family and friendships within a life span context. In: Blieszner R,
Bedford VH (eds) Handbook of aging and the family. Greenwood Press, Westport, CT, pp 355-372

Ashida S, Heaney CA (2008) Differential associations of social support and social connectedness with structural features of social networks and the health status of older adults. J Aging Health 20:872-893. https://doi.org/10.1177/0898264308324626

Bengtson VL (2001) Beyond the nuclear family: the increasing importance of multigenerational bonds. J Marriage Fam 63:1-16

Bloem BA, van Tilburg TG, ThomÉse F (2008) Changes in older Dutch adults' role networks after moving. Pers Relat 15:465-478. https:// doi.org/10.1111/j.1475-6811.2008.00210.x

Börsch-Supan A (2020) Survey of health, ageing and retirement in Europe (SHARE) wave 6. Release version: 7.1.0. SHARE-ERIC. https://doi.org/10.6103/SHARE.w6.710

Börsch-Supan A, Brandt M, Hunkler C et al (2013) Data resource profile: the survey of health, ageing and retirement in Europe (SHARE). Int J Epidemiol. https://doi.org/10.1093/ije/dyt088

Bucx F, van Wel F, Knijn T (2012) Life course status and exchanges of support between young adults and parents. J Marriage Fam 74:101-115. https://doi.org/10.1111/j.1741-3737.2011.00883.x

Carstensen LL (1992) Social and emotional patterns in adulthood: support for socioemotional selectivity theory. Psychol Aging 7:331-338. https://doi.org/10.1037/0882-7974.7.3.331

Cheng ST, Lee CKL, Chan ACM, et al (2009) Social network types and subjective well-being in Chinese older adults. J Gerontol Ser B Psychol Sci Soc Sci 64:713-722. https://doi.org/10.1093/ geronb/gbp075

Cohn-Schwartz E, Levinsky M, Litwin H (2020) Social network type and subsequent cognitive health among older Europeans. Int Psychogeriatr. https://doi.org/10.1017/S1041610220003439

Collins LM, Lanza ST (2009) Latent class and latent transition analysis. Wiley, Hoboken, NJ, USA 
Collins LM, Lanza ST (2010) Latent Class and Latent Transition Analysis: With applications in the social, behavioral, and health sciences. John Wiley \& Sons, Inc., Hoboken, New Jersey

Cornwell B, Laumann EO, Schumm LP (2008) The social connectedness of older adults: a national profile. Am Sociol Rev 73:185203. https://doi.org/10.1177/000312240807300201

Cornwell E, Goldman AW (2021) Local ties in the social networks of older adults. J Gerontol: Series B. https://doi.org/10.1093/geronb/ gbaa033

de Jong Gierveld J, Perlman D (2006) Long-standing nonkin relationships of older adults in the Netherlands and the United States. Res Aging 28:730-748. https://doi.org/10.1177/0164027506291873

Djundeva M, Dykstra PA, Fokkema T (2019) Is living alone "aging alone"? Solitary living, network types, and well-being. J Gerontol - Series B Psychol Sci Soc Sci 74:1406-1415. https://doi.org/10. 1093/geronb/gby119

Dykstra PA (2018) Cross-national differences in intergenerational family relations: the influence of public policy arrangements. Innov Aging 2:1-8. https://doi.org/10.1093/geroni/igx032

Ellwardt L, Aartsen M, van Tilburg T (2017) Types of non-kin networks and their association with survival in late adulthood: a latent class approach. J Gerontol - Series B Psychol Sci Soc Sci 72:694-705. https://doi.org/10.1093/geronb/gbw142

Fihel A, Kalbarczyk M, Nicińska A (2021) Childlessness, geographical proximity and non-family support in 12 European countries. Ageing Soc. https://doi.org/10.1017/s0144686x21000313

Finchum TD (2005) Keeping the ball in the air: contact in longdistance friendships. J Women Aging 17:91-106. https://doi. org/10.1300/J074v17n03_07

Fiori KL, Antonucci TC, Akiyama H (2008) Profiles of social relations among older adults: a cross-cultural approach. Ageing Soc 28:203-231. https://doi.org/10.1017/S0144686X07006472

Fiori KL, Antonucci TC, Cortina KS (2006) Social network typologies and mental health among older adults. J Gerontol: Psychol Sci 61:25-32. https://doi.org/10.1093/geronb/61.1.P25

Fiori KL, Jager J (2012) The impact of social support networks on mental and physical health in the transition to older adulthood: a longitudinal, pattern-centered approach. Int J Behav Dev 36:117-129. https://doi.org/10.1177/0165025411424089

Fiori KL, Smith J, Antonucci TC (2007) Social network types among older adults: a multidimensional approach. J Gerontol Series B, Psychol Sci Soc Sci 62:P322-P330

Fischer CS (1982) To dwell among friends: Personal networks in town and city. University of Chicago Press, Chicago, IL

Frei A, Axhausen KW (2007) Size and structure of social network geographies. Arbeitsberichte Verkehrs-und Raumplanung, 1-33. https://doi.org/10.3929/ethz-a-005562753

Golden J, Conroy RM, Lawlor BA (2009) Social support network structure in older people: underlying dimensions and association with psychological and physical health. Psychol Health Med 14:280-290. https://doi.org/10.1080/13548500902730135

Goldman AW, Cornwell B (2018) Social disadvantage and instability in older adults' ties to their adult children. J Marriage Fam 80:1314-1332. https://doi.org/10.1111/jomf.12503

Ha JH, Carr D (2005) The effect of parent-child geographic proximity on widowed parents' psychological adjustment and social integration. Res Aging 27:578-610. https://doi.org/10.1177/ 0164027505277977

Hank K (2007) Proximity and contacts between older parents and their children: a European comparison. J Marriage Fam 69:157173. https://doi.org/10.1111/j.1741-3737.2006.00351.x

Harper M-G, Wellman B, Quan-Haase A (2020) Older adults and information and communication technologies in the global north. Encycl Gerontol Popul Aging. https://doi.org/10.1007/ 978-3-319-69892-2_902-1
Hogerbrugge MJA, Silverstein MD (2014) Transitions in relationships with older parents: from middle to later years. J Gerontol - Series B Psychol Sci Soc Sci 70:481-495. https://doi.org/10. 1093/geronb/gbu069

Inglehart R (2020) Modernization and postmodernization: cultural, economic and political change in 43 societies. Princeton University Press

Iveniuk J, Donnelly P, Hawkley L (2020) The death of confidants and changes in older adults' social lives. Res Aging 42:236-246. https://doi.org/10.1177/0164027520917061

Jacobs MT, Broese Van Groenou MI, Aartsen MJ, Deeg DJH (2018) Diversity in older adults' care networks: the added value of individual beliefs and social network proximity. J Gerontol Series B Psychol Sci Soc Sci 73:326-336. https://doi.org/10. 1093/geronb/gbw012

Kalmijn M (2006) Educational inequality and family relationships: influences on contact and proximity. Eur Sociol Rev 22:1-16. https://doi.org/10.1093/esr/jci036

Kaptijn R, Thomese F, van Tilburg TG, Liefbroer AC (2010) How grandparents matter. Hum Nat 21:393-405. https://doi.org/10. 1007/s12110-010-9098-9

Klein Ikkink K, van Tilburg T (1999) Broken ties: reciprocity and other factors affecting the termination of older adults' relationships. Soc Netw 21:131-146. https://doi.org/10.1016/S03788733(99)00005-2

Koelet S, Van Mol C, De Valk HAG (2017) Social embeddedness in a harmonized Europe: the social networks of European migrants with a native partner in Belgium and the Netherlands. Global Netw 17:441-459. https://doi.org/10.1111/glob.12123

Kohli M, Hank K, Künemund H (2009) The social connectedness of older Europeans: patterns, dynamics and contexts. J Eur Soc Policy 19:327-340. https://doi.org/10.1177/1350506809341514

Letki N (2017) Trust in newly democratic regimes. Oxford University Press

Litwin H (2001) Social network type and morale in old age. Gerontologist 41:516-524. https://doi.org/10.1093/geront/41.4.516

Litwin H (2009) Social networks and well-being: a comparison of older people in Mediterranean and non-Mediterranean countries. J Gerontol - Series B Psychol Sci Soc Sci 65:599-608. https://doi.org/ 10.1093/geronb/gbp104

Litwin H (2003) The association of disability, sociodemographic background, and social network type in later life. J Aging Health 15:391-408. https://doi.org/10.1177/0898264303015002004

Litwin H, Levinsky M, Schwartz E (2019) Network type, transition patterns and well-being among older Europeans. Eur J Ageing. https://doi.org/10.1007/s10433-019-00545-7

Litwin H, Shiovitz-Ezra S (2011) Social network type and subjective well-being in a national sample of older Americans. Gerontologist 51:379-388. https://doi.org/10.1093/geront/gnq094

Litwin H, Shiovitz-Ezra S (2006) Network type and mortality risk in later life. Gerontologist 46:735-743. https://doi.org/10.1093/geront $/ 46.6 .735$

Litwin H, Stoeckel KJ (2013) Confidant network types and well-being among older Europeans. Gerontologist 54:762-772. https://doi. org/10.1093/geront/gnt056

Logan JR, Spitze GD (1994) Family neighbors. Am J Sociol 100:453476. https://doi.org/10.1086/230543

Lovén I, Hammarlund C, Nordin M (2020) Staying or leaving? the effects of university availability on educational choices and rural depopulation. Pap Reg Sci 99:1339-1365. https://doi.org/ 10.1111/pirs. 12530

Lynch SM, Taylor MG (2016) Trajectory models in aging research. Handbook of aging and the social sciences. Academic Press, San Diego, pp 23-51 
Mair CA, Carr D (2019) Alternatives to aging alone?: "kinlessness" and the importance of friends across European contexts. J Gerontol- Series B Psychol Sci Soc Sci 74:1416-1428. https://doi. org/10.1093/geronb/gbz029

Malter F, Börsch-Supan A (2017) SHARE Wave 6: Panel innovations and collecting Dried Blood Spots. Max Planck Institute for Social Law and Social Policy, Munich: MEA

Menec VH, Newall NE, Mackenzie CS et al (2019) Examining individual and geographic factors associated with social isolation and loneliness using Canadian longitudinal study on aging (CLSA) data. PLoS ONE 14:1-18. https://doi.org/10.1371/ journal.pone.0211143

Mitchell MN (2021) Interpreting and visualizing regression models using Stata. Stata Press

Mok D, Wellman B, Carrasco J (2010) Does distance matter in the age of the internet? Urban Stud 47:2747-2783. https://doi.org/ 10.1177/0042098010377363

Mudrazija S, Angel JL, Cipin I, Smolic S (2020) Living alone in the United States and Europe: the impact of public support on the independence of older adults. Res Aging 42:150-162. https:// doi.org/10.1177/0164027520907332

Nguyen AW (2017) Variations in social network type membership among older African Americans, Caribbean blacks, and nonHispanic whites. J Gerontol - Series B Psychol Sci Soc Sci 72:716-726. https://doi.org/10.1093/geronb/gbx016

Park S, Smith J, Dunkle RE (2014) Social network types and wellbeing among south Korean older adults. Aging Ment Health 18:72-80. https://doi.org/10.1080/13607863.2013.801064

Perlman D, Peplau A (1981) Toward a social psychology of solidarity. Pers Relat 3:31-56. https://doi.org/10.1037/0003-066X.41.2.229

Perry BLB, Pescosolido BAB, Borgatti SP (2018) Egocentric network analysis: foundations, methods, and models. Cambridge University Press

Quan-Haase A, Mo GY, Wellman B (2017) Connected seniors: how older adults in east York exchange social support online and offline. Inf Commun Soc 20:967-983. https://doi.org/10.1080/ 1369118X.2017.1305428

Quan-haase A, Williams C, Kicevski M, et al (2018) Dividing the grey divide: deconstructing myths about older adults' online activities, skills, and attitudes. https://doi.org/10.1177/0002764218777572

Reher DS (1998) Family ties in western Europe: persistent contrasts. Popul Dev Rev 24:203. https://doi.org/10.2307/2807972

Rérat P (2014) The selective migration of young graduates: which of them return to their rural home region and which do not? J Rural Stud 35:123-132. https://doi.org/10.1016/j.jrurstud.2014.04.009

Rosenmayr L, Köckeis E (1963) Propositions for a sociological theory of ageing and the family. Int Soc Sci J 15:410

Schmidt T, Christiansen LB, Schipperijn J, Cerin E (2021) Social network characteristics as correlates and moderators of older adults' quality of life-the SHARE study. Eur J Pub Health. https://doi. org/10.1093/eurpub/ckab001

Small ML (2013) Weak ties and the core discussion network: why people regularly discuss important matters with unimportant alters. Soc Netw 35:470-483. https://doi.org/10.1016/j.socnet.2013.05. 004

Small ML, Adler L (2019) The role of space in the formation of social ties. Ann Rev Sociol 45:111-132. https://doi.org/10.1146/annur ev-soc-073018-022707

Small ML, Sukhu C (2016) Because they were there: access, deliberation, and the mobilization of networks for support. Soc Netw 47:73-84. https://doi.org/10.1016/j.socnet.2016.05.002
Sohn SY, Tak JW, Kim WJ et al (2017) Social network types among older Korean adults: associations with subjective health. Soc Sci Med 173:88-95. https://doi.org/10.1016/j.socscimed.2016.11.042

Spring A, Ackert E, Crowder K, South SJ (2017) Influence of proximity to kin on residential mobility and destination choice: examining local movers in metropolitan areas. Demography 54:1277-1304. https://doi.org/10.1007/s13524-017-0587-x

Stoeckel KJ, Litwin H (2016) The impact of social networks on the relationship between functional impairment and depressive symptoms in older adults. Int Psychogeriatr 28:39-47. https://doi.org/ $10.1017 /$ S 1041610215000538

Stoeckel KJ, Litwin H (2015) Accessibility to neighbourhood services and well-being among older Europeans. In: Börsch-Supan A, Kneip T, Litwin $\mathrm{H}$ et al (eds) Ageing in Europe - supporting policies for an inclusive society. De Gruyter, pp 39-48

Suanet B, Antonucci TC (2017) Cohort differences in received social support in later life: the role of network type. J Gerontol - Series B Psychol Sci Soc Sci 72:706-715. https://doi.org/10.1093/geronb/gbw075

Szabo A, Stephens C, Allen J, Alpass F (2016) Construct validation of Wenger's support network typology. 00:1-6. https://doi.org/ 10.1093/geronb/gbw126 Szabo A, Stephens C, Allen J, Alpass F (2016) Construct validation of Wenger' s support network typology. https://doi.org/10.1093/geronb/gbw126

Tomassini C, Kalogirou S, Grundy E et al (2004) Contacts between elderly parents and their children in four European countries: current patterns and future prospects. Eur J Ageing 1:54-63. https:// doi.org/10.1007/s10433-004-0003-4

Torres S (2019) On elastic ties: distance and intimacy in social relationships. Sociol Sci 6:235-263. https://doi.org/10.15195/V6.A10

Viry G (2012) Residential mobility and the spatial dispersion of personal networks: effects on social support. Soc Netw 34:59-72. https://doi.org/10.1016/j.socnet.2011.07.003

Vozikaki M, Papadaki A, Linardakis M, Philalithis A (2018) Loneliness among older European adults: results from the survey of health, aging and retirement in Europe. J Pub Health (germany) 26:613-624. https://doi.org/10.1007/s10389-018-0916-6

Vriens E, van Ingen E (2018) Does the rise of the internet bring erosion of strong ties? analyses of social media use and changes in core discussion networks. New Media Soc 20:2432-2449. https://doi. org/10.1177/1461444817724169

Ward R, Deane G, Spitze G (2014) Life-course changes and parentadult child contact. Res Aging 36:568-602. https://doi.org/10. $1177 / 0164027513510325$

Wellman B (1992) Which ties provide what kinds of support? Adv Group Process 9:207-235

Wenger GC (1991) A network typology: from theory to practice. J Aging Stud 5:147-162. https://doi.org/10.1016/0890-4065(91) 90003-B

Wenger GC, Davies R, Shahtahmasebi S, Scott A (1996) Social isolation and loneliness in old age: review and model refinement. Ageing Soc 16:333-358. https://doi.org/10.1017/S0144686X0 0003457

Wrzus C, Hänel M, Wagner J, Neyer FJ (2013) Social network changes and life events across the life span: a meta-analysis. Psychol Bull 139:53-80. https://doi.org/10.1037/a0028601

Publisher's Note Springer Nature remains neutral with regard to jurisdictional claims in published maps and institutional affiliations. 